\title{
The Validity and Reliability Study of Turkish Version of Work-Related Flow Inventory (WOLF)
}

\author{
Aysu Zekioğlu ${ }^{1}$ \\ Trakya University
}

\author{
Sabahattin Tekingündüz ${ }^{2}$ \\ Mersin University
}

\author{
Önder Sünbül ${ }^{3}$ \\ Mersin University
}

\begin{abstract}
This study aims at determining the reliability and validity of the work-related flow inventory (WOLF). WOLF was developed by Bakker in 2008 and contains 13 items with three dimensions (absorption [4 items], enjoyment [4 items], and intrinsic work motivation [5 items]). This inventory was originally conducted over seven employees who work at companies in the Netherlands. Yalçınkaya translated WOLF into Turkish and conducted the validity and reliability of the inventory, but according to her study's results, she had reduced 13 items to 12 and three dimensions to two. In our study, Bakker first provided a letter of permission, after which the inventory was translated into Turkish by a specialist. The Turkish version of WOLF was conducted over 40 health employees working at a university hospital in Edirne. Three weeks later, measures were performed again; we examined the WOLF inventory as performed by Bakker in 2008, and completely validated 13 items and three dimensions. The Turkish version of WOLF can be used in research to determine the effects of work-related flow on the workforce in health services.
\end{abstract}

Keywords

Hospital • Validity $\bullet$ Reliability $\bullet$ Work $\bullet$ Flow

\footnotetext{
1 Correspondence to: Aysu Zekioğlu (Asst. Prof.), Health Management Department, Faculty of Health Sciences, Trakya University. Email: aysukurtuldu@trakya.edu.tr

2 Asst. Prof., Health Management Department, School of Health, Mersin University. Email: stekingunduz@mersin.edu.tr

3 Asst. Prof., Educational Measurement and Evaluation Department, Mersin University. Email: ondersunbul@mersin.edu.tr

Citation: Zekioğlu, A., Tekingündüz, S., \& Sünbül, Ö. (2017). The validity and reliability study of Turkish version of Work-related Flow Inventory (WOLF). Sanitas Magisterium, 3, 61-67. http://dx.doi.org/10.12738/SM.2017.1.0025
} 
Work is an important area in human life. Work life offers social and economic networks among people. After the Industrial Revolution, work life changed from human power to machine power. Meanwhile, people's education, skills, competences, and behaviors became the core elements of production.

Human behaviors in the workplace are related to different components such as performance, motivation, decision making, and team work. Because of this situation, researchers in the literature on organizational behavior have performed various scales for examining the effects of human behavior in an organization. Flow is an important subject not only in sports, art, and music, but also in work life. In the literature, flow means something "that many people have used to describe the sense of effortless action they feel in moments that stand out as the best in their lives" (Csikszentmihalyi, 1997, p. 29). According to this definition, people are focused intently on their work during flow, and this situation increases one's motivation. Flow has three components:

(a) Absorption. Flow theory argues that an acceptable level of absorption contributes to improving employees' skills and competences (Eisenberger, Jones, Stinglhamber, Shanock, \& Randall, 2005, p. 771). Employees concentrate on their work. They forget all other things and time passes quickly in the workplace (Bakker, 2008, p. 401).

(b) Enjoyment. The role of positive psychology is important in organizational behavior. Employees who enjoy their job are more powerful and more successful than others. Thanks to enjoyment, the quality of work life increases. Furthermore, enjoyment is related to autonomy, well-being, and satisfaction (Wilkes, Doull, Chok, \& Mashingaidze, 2015, p. 657). Having fun at work and enjoyment can improve employees' organizational commitment levels (Plester \& Hutchison, 2016, p. 1).

(c) Intrinsic motivation. Motivation is a social concept that creates an organizational climate by means of the social relations among employees (Massenberg, Spurk, \& Kauffeld, 2015, p. 164). Motivation has three types: intrinsic motivation, extrinsic motivation, and amotivation (Pelletier, Tuson, \& Haddad, 1997, p. 415). Intrinsic motivation increases job satisfaction, organizational commitment, productivity, and performance; also, employees are continually interested in their jobs (Georgellis, Iossa, \& Tabvuma, 2011, p. 473; Salanova, Bakker, \& Llorens, 2006, p. 2). Research in the literature emphasizes that intrinsic motivation creates a connection between social environment and creativity (Isaksen, Murdock, Firestien, \& Treffinger, 1993, p. 405).

Csikszentmihalyi (1997) stated that, "to live [means to] live in fullness and use time effectively" both in life overall and at work. On the other hand, people mainly experience flow at work life, and this experience is related to high cognitive involvement (Csikszentmihalyi, 1997; Clarke \& Haworth, 1994, p. 511). According to the results of Massenger's research (2006), both personal resources such as self- 
efficacy and organizational resources such as social support climate and clear goals positively affect work-related flow.

\section{Purpose}

The aim of this study is to determine the reliability and validity of WOLF, the work-related flow inventory.

\section{Method}

Data have been collected within the context of an adaptation study and subjected to a reliability and validity study. Within the context of the validity study, various factorial constructs have been tested for construct validity within the framework of confirmatory factor analysis. The eventual construct reached within the context of the validity study has been investigated from the viewpoints of internal consistency and test-retest reliability. Repeated measurements have been made using 40 health-staff employees for test-retest reliability. In addition to this, the items positioned in the construct that was eventually reached have been included in an investigation of the items' distinctiveness; the item-total correlation test results were investigated by calculating the Pearson product-moment correlation coefficient separately for each factor.

\section{Research Design}

WOLF was developed by Bakker in 2008; it has 13 items and three dimensions (absorption [4 items], enjoyment [4 items], and intrinsic work motivation [5 items]). The inventory was initially performed over seven employees working at companies in the Netherlands. Yalçınkaya (2013) had translated WOLF into Turkish and conducted a validity and reliability study of the inventory, but according to her study's results, she had reduced 13 items to 12 items and three dimensions to two. In our study, a letter of permission was first received from Bakker, after which the inventory was translated into Turkish by a specialist.

\section{Universe and Sampling}

The Turkish version of WOLF was conducted over 40 health-staff employees working at a university hospital in Edirne. Three weeks later, repeated measures were performed. Only voluntary participants were included in the research.

\section{Data Analysis}

In Bakkar's (2008) study undertaken with different work groups, the validity and reliability of WOLF, consisting of 13 items and three dimensions, was laid out. The Turkish adaptation study of the inventory was carried out by Yalçınkaya (2013) with 
84 employees on duty at a public bank. In the study performed by Yalçınkaya (2013), a construct consisting of 12 items and two dimensions was suggested for WOLF. This suggested construct, together with the suggested item positioning, has again been subjected to confirmatory factor analysis in the new collection of data. The model achieved as a result of analysis is presented in Figure 1.

Although all factor loadings occurring in Figure 1's model are significant, after investigating the compatibility statistics regarding the model, one can conclude that the model is incompatible. In other words, the previously suggested modeling is incompatible with and does not verify the present data. The modeling for confirmatory factor analysis regarding the scale's original 13-item, three-dimensional construct takes place in Figure 2.

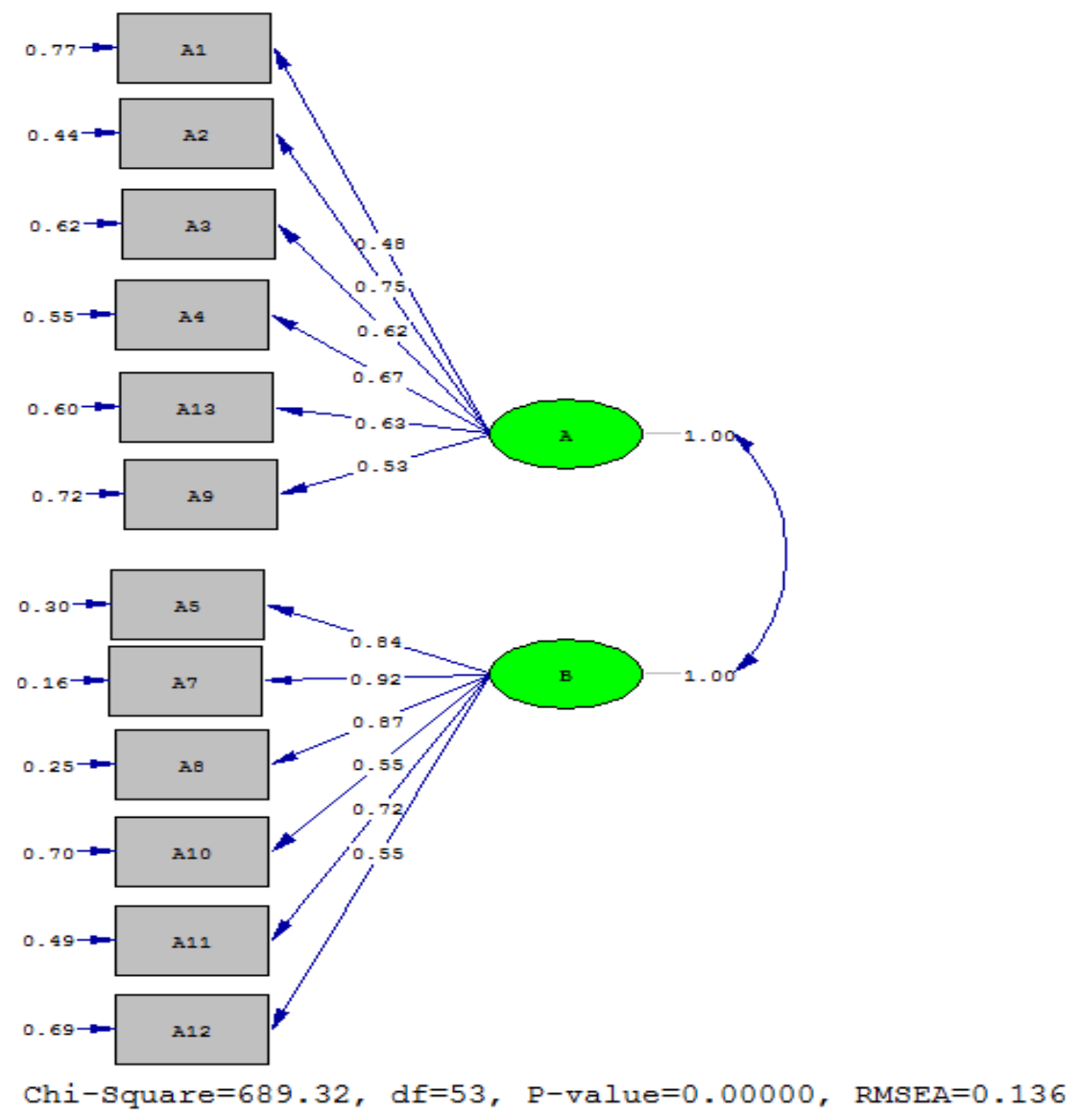

Figure 1. Analyzing 12 Items with Two Factors. 


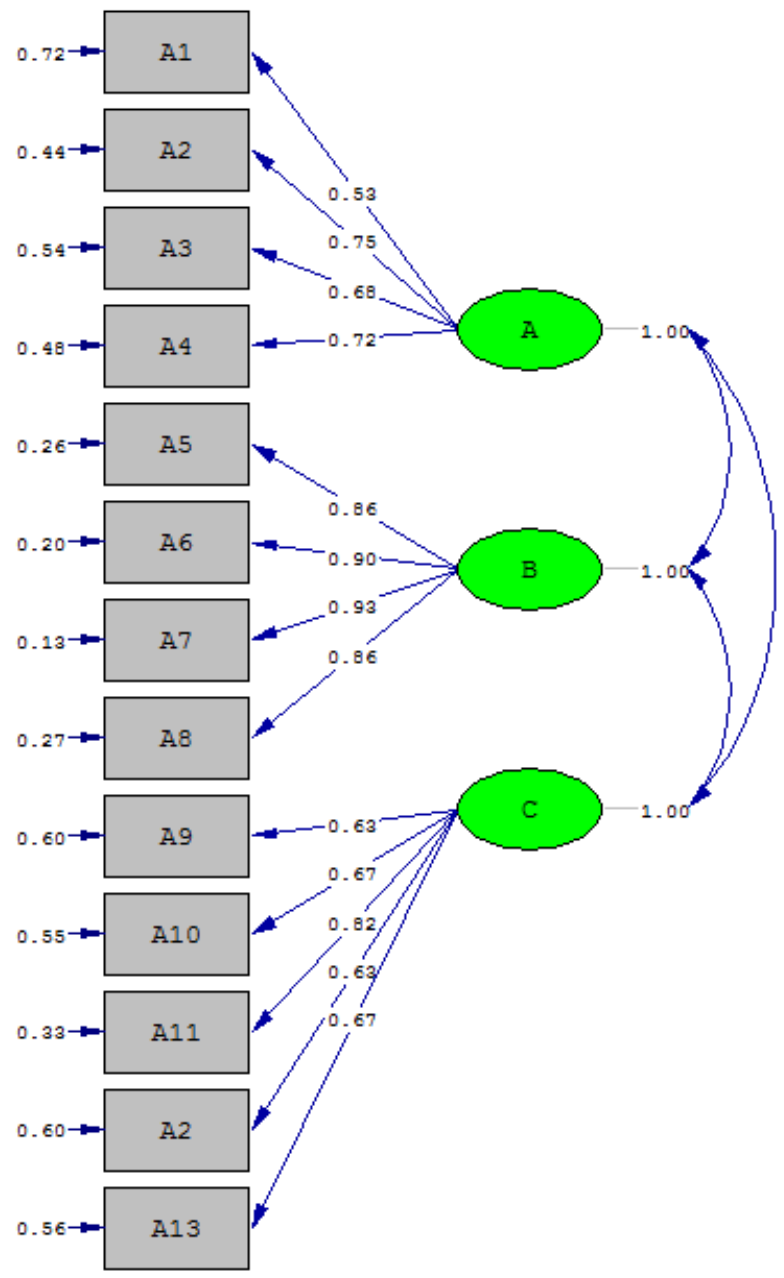

Figure 2. The Modeling Result Regarding the Original 13-Item, Three-Factor Construct.

When investigating $t$-values regarding item- and dimension-load distribution, one sees that all the connections taking part in the model are significant. Meanwhile, compatibility statistics regarding the model are $\overline{\mathrm{x}}=428.61(p=.0) ; R M S E A=0.095$ $(0.087 ; 0.10) ; G F I=0.91 ; N N F I=0.92 ;$ and $C F I=0.93$.

Accordingly, the model can be said to generally satisfy the requirements of compatibility statistics. In terms of this model, which has been verified, one can see that Factor A has four items (A1, A2, A3, A4) and Factor B has four items (A5, A6, A7, A8), while Factor C has five items (A9, A10, A11, A12, A13). The item distinctiveness coefficients and reliability coefficients according to factors are shown in Table 1. 
Table 1

Item and Test Psychometric Characteristics Based on a Three-Factor Analysis

\begin{tabular}{|c|c|c|c|c|}
\hline Factor & Item No. & $\begin{array}{c}\text { Item } \\
\text { Total Test } \\
\text { Correlation }\end{array}$ & $\begin{array}{l}\text { Cronbach } \\
\text { Alpha }\end{array}$ & Test/Re-test \\
\hline \multirow{4}{*}{ A } & A1 When I am working, I think about nothing else & 0.520 & \multirow{4}{*}{0.775} & \multirow{4}{*}{$0.927^{*}$} \\
\hline & A2 I get carried away by my work & 0.530 & & \\
\hline & A3 When I am working, I forget everything else around me & 0.645 & & \\
\hline & A4 I am totally immersed in my work & 0.618 & & \\
\hline \multirow{4}{*}{ B } & A5 My work gives me a good feeling & 0.823 & \multirow{4}{*}{0.935} & \multirow{4}{*}{$0.859 *$} \\
\hline & A6 I do my work with a lot of enjoyment & 0.862 & & \\
\hline & A7 I feel happy during my work & 0.897 & & \\
\hline & A8 I feel cheerful when I am working & 0.808 & & \\
\hline \multirow{5}{*}{$\mathrm{C}$} & A9 I would still do this work, even if I earned less pay & 0.587 & \multirow{5}{*}{0.816} & \multirow{5}{*}{$0.947^{*}$} \\
\hline & A10 I find that I also want to work in my free time & 0.619 & & \\
\hline & A11 I work because I enjoy it & 0.693 & & \\
\hline & $\begin{array}{l}\text { A12 When I am working on something, I am doing it for } \\
\text { myself }\end{array}$ & 0.555 & & \\
\hline & $\begin{array}{l}\text { A13 I get my motivation from the work itself, not from the } \\
\text { reward for it }\end{array}$ & 0.583 & & \\
\hline
\end{tabular}
$* p<.01$.

When investigating Table 1, all item-total correlation test values of the items that occur in Factor A are greater than 0.30; in other words, all of this factor's items are significant. When investigating the Cronbach alpha value calculated for internal consistency of the related factor $(\alpha=0.775)$ and the Pearson product-moment correlation coefficient calculated for test re-test reliability, a rather high value is found ( $r=0.927$ ). From this point of view, the first domain can be said to be reliable in the contexts of both internal consistency and stability. All item-total correlation test values for Factor-B items are greater than 0.30; in other words, they are all significant. When investigating the Cronbach alpha value calculated for Factor B's internal consistency ( $\alpha$ $=0.935)$ and the Pearson product-moment correlation coefficient calculated for test retest reliability, a rather high value is found $(r=0.859)$. From this point of view, Factor $\mathrm{B}$ can be said to be reliable in the context of both internal consistency and stability. All item-total correlation test values of Factor-C items are greater than 0.30 ; in other words, all items in this sub-factor are significant. When examining the Cronbach alpha value calculated for Factor C's internal consistency $(\alpha=0.816)$ and the Pearson productmoment correlation coefficient calculated for test re-test reliability, a rather high value is found $(r=0.947)$. From this point of view, the third domain can be said to be reliable in the contexts of both internal consistency and stability.

\section{Conclusion}

Labor force is a core component in health services. In the health sector, labor force's attitudes are strongly related to organizational performance. Flow is as important as other factors such as motivation and satisfaction in improving organizational 
performance. In this study, we examined the WOLF inventory, developed and entirely validated by Bakker in 2008 with 13-items and three dimensions. The Turkish version of WOLF can be used in research to determine the effects of work-related flow on the healthcare workforce.

\section{References}

Bakker, A. (2008). The work-related flow inventory: Construction and initial validation of the WOLF. Journal of Vocational Behavior, 72(3), 400-414. http://dx.doi.org/10.1016/j.jvb.2007.11.007

Clarke, S., \& Haworth, J. (1994). 'Flow' experience in the daily lives of sixth-form college students, British. Journal of Psychology, 85(4), 511-523. http://dx.doi.org/10.1111/j.2044-8295.1994. tb02538.x

Csikszentmihalyi, M. (1997). Finding flow: The psychology of engagement with everyday life. New York, NY: Harper Collins Publisher.

Eisenberger, R., Jones, J., Stinglhamber, F., Shanock, L., \& Randall, A. (2005). Flow experiences at work: For high need achievers alone? Journal of Organizational Behavior 26(7), 755-775. http://dx.doi.org/10.1002/job.337

Georgellis, Y., Iossa, E., \& Tabvuma, V. (2011). Crowding out intrinsic motivation in the public sector. Journal of Public Administration Research and Theory, 21(3), 473-493. http://dx.doi. org/10.1093/jopart/muq073

Isaksen, S., Murdock, M., Firestien, R., \& Treffinger, D. (1993). Understanding and recognizing creativity: The emergence of a discipline. New York, NY: Ablex Publishing.

Massenberg, A., Spurk, D., \& Kauffeld, S. (2015). Social support at the workplace, motivation to transfer and training transfer: A multilevel indirect effects model. International Journal of Training and Development, 19(3), 161-178. http://dx.doi.org/10.1111/ijtd.12054

Pelletier, L., Tuson, K., \& Haddad, N. (1997). Client motivation for therapy scale: A measure of intrinsic motivation, extrinsic motivation, and amotivation for therapy. Journal of Personality Assessment, 68(2), 414-435.

Plester, B., \& Hutchison, A. (2016). Fun times: The relationship between fun and workplace engagement. Employee Relations: The International Journal, 38(3), 1-19. http://dx.doi. org/10.1108/ER-03-2014-0027

Salanova, M., Bakker, A., \& Llorens, S. (2006). Flow at work: Evidence for an upward spiral of personal and organizational resources. Journal of Happiness Studies, 7, 1-22. http://dx.doi. org/10.1007/s10902-005-8854-8

Wilkes, L., Doull, M., Chok, H., \& Mashingaidze, G. (2015). Enjoyment in nursing - Experiences from the clinical milieu. Journal of Clinical Nursing, 25, 656-663. http://dx.doi.org/10.1111/ jocn. 12981

Yalçınkaya, P. (2013). Kendini İşe Kaptırma Ölçeği: Uyarlama çalışması [WOLF: An adaptation study]. The Sakarya Journal of Economics, 1, 66-87. 
